\title{
Two new endemic genera and a new species of toad (Anura: Bufonidae) from the Western Ghats of India SD Biju ${ }^{1}$, Ines Van Bocxlaer ${ }^{2}$, Varad B Giri ${ }^{3}$, Simon P Loader ${ }^{4}$ and Franky Bossuyt*2
}

Address: ${ }^{1}$ Systematics Lab, Centre for Environmental Management of Degraded Ecosystems (CEMDE), School of Environmental Studies, University of Delhi 110007 , India, ${ }^{2}$ Biology Department, Unit of Ecology \& Systematics: Amphibian Evolution Lab, Vrije Universiteit Brussel (VUB), Pleinlaan 2, B-1050 Brussels, Belgium, ${ }^{3}$ Collections Department, Bombay Natural History Society (BNHS), S.B. Singh Road, Mumbai 400 001, India and ${ }^{4}$ Institute of Biogeography, Department of Environmental Sciences, University of Basel, Klingelbergstrasse 27, 4056 Basel, Switzerland

Email: SD Biju - sdbiju@cemde.du.ac.in; Ines Van Bocxlaer - ivbocxla@vub.ac.be; Varad B Giri - varadgiri@gmail.com; Simon P Loader - Simon.Loader@unibas.ch; Franky Bossuyt* - fbossuyt@vub.ac.be

* Corresponding author

Published: 7 December 2009

BMC Research Notes 2009, 2:24| doi:|0.||86/|756-0500-2-24|
Received: 7 May 2009

Accepted: 7 December 2009

This article is available from: http://www.biomedcentral.com/l756-0500/2/24I

(C) 2009 Bossuyt et al; licensee BioMed Central Ltd.

This is an Open Access article distributed under the terms of the Creative Commons Attribution License (http://creativecommons.org/licenses/by/2.0), which permits unrestricted use, distribution, and reproduction in any medium, provided the original work is properly cited.

\begin{abstract}
Background: Bufonidae are a large family of toads with a subcosmopolitan distribution. Recent molecular phylogenetic analyses have revealed a radiation of toads (Adenominae) with distinct adult and larval ecomorphs on the Southern parts of the Indian subcontinent. The Indian torrential species "Ansonia" ornata has a basal position in this clade and does not group with South-East Asian Ansonia. Additionally, the nested position of "Bufo" koynayensis and an undescribed sister species, and their distinct ecologies including a non-typical egg-laying strategy within bufonids, support the recognition of a second distinct genus. In this paper we describe two new genera and one new species from the Adenominae clade.

Findings: Ansonia ornata Günther, 1876 " 1875 " is transferred to Ghatophryne gen. nov., a genus of torrentially adapted toads that are endemic to the Western Ghats of India. On the basis of close morphological resemblance and distribution, Ansonia rubigina Pillai and Pattabiraman, 198I is provisionally transferred to this new genus. The Western Ghats endemic toad Bufo koynayensis Soman, 1963 is transferred to a new genus Xanthophryne gen. nov. Based on molecular and morphological evidence, we additionally describe a new species, Xanthophryne tigerinus sp. nov., from Amboli in the Western Ghats.

Conclusion: The descriptions and subsequent taxonomic changes we propose result in three genera of bufonids recognised as being endemic to the Western Ghats (Ghatophryne gen. nov., Xanthophryne gen. nov. and Pedostibes), and one to Sri Lanka (Adenomus). The spatial distribution, and arrangement of these lineages at the base of Adenominae diversification, reflects their Early Neogene isolation in the Western Ghats-Sri Lanka hotspot.
\end{abstract}




\section{Introduction}

Bufonidae are a family of toads with over 500 extant species distributed on most continents. Current opinions on bufonid taxonomy are very divergent, and range from the recognition of multiple genera [1], to favouring a subcosmopolitan genus Bufo with plenty of subgenera [2]. Although the phylogenetic relationships of bufonids have been studied intensively $[1,3,4]$, the evolutionary position of species on the Indian subcontinent had remained unclear. However, recent molecular phylogenetic analyses revealed that these toads belong to a radiation containing distinct ecomorphs in adult and/or larval forms [5]. The early diversification of this clade, for which the name Adenominae is available [6], has been reconstructed as occurring on the Southern parts of the Indian subcontinent. Early diversification of Adenominae, timed at the early Miocene, led to several endemic lineages ("Ansonia" ornata, Pedostibes tuberculosus, the "Bufo" koynayensis group and Adenomus) [5] and to the origin of the more widespread Duttaphrynus clade. The unexpected evolutionary position of "Ansonia" ornata and "Bufo" koynayensis (see abstract) requires recognition of two new genera to accommodate these Western Ghats endemic species and their relatives.

\section{Methods}

Collection of amphibian specimens was made during fieldtrips in the Western Ghats between 1997 and 2002. Specimens were preserved in 5\% formaldehyde for 2 days, and subsequently transferred to $70 \%$ ethanol. Measurements were taken to the nearest $0.1 \mathrm{~mm}$, using a digital slide-caliper or a binocular microscope with a micrometer ocular. The description (all measurements in $\mathrm{mm}$ ) of the types follows terminology used elsewhere [7]. To comply with regulations of the International Code of Zoological Nomenclature we have deposited copies of this article at the following publicly accessible libraries: Bombay Natural History Society, Mumbai, India (BNHS); Koninklijk Belgisch Instituut voor Natuurwetenschappen, Brussels, Belgium (KBIN); Natural History Museum, London, UK (BMNH); American Museum of Natural History, New York, USA (AMNH); Museum National d'Histoire Naturelle, Paris, France (MNHN); Russian Academy of Sciences, Moscow, Russia (RAS).

\section{Descriptions}

\section{Ghatophryne gen. nov. (Figure I) \\ Etymology}

The generic epithet is derived from the words 'Ghats' and 'phryne'. The former is the Sanskrit word for 'steps' and refers to the Western Ghats mountain range, where this genus is endemic, while 'phryne' means toad in Greek.

\section{Type species}

Ansonia ornata Günther, "1876" 1875, by original designation.

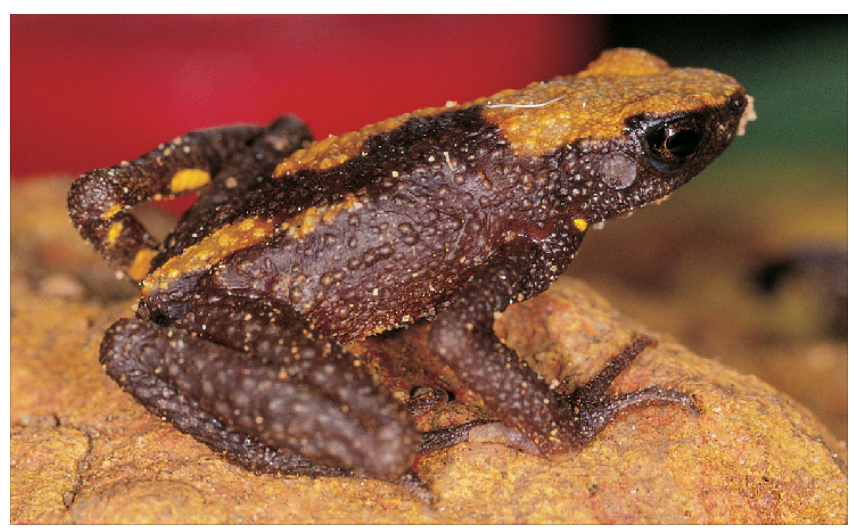

Figure I

Ghatophryne ornata specimen SDB 636 I, adult male, SVL $29.2 \mathrm{~mm}$, collected from Kurichiyarmala, I I $35^{\prime} N, 7^{\circ} 58 ' E$, Wayanad, Kerala.

The original description of this species was based on nine syntypes (BMNH 1947.2.20.65-1947.2.20.73) collected in "Bramagherries" (= Brahmagiri Hills, Coorg) by R. H. Beddome. We hereby designate one of them, BMNH 1947.2.20.66 (ex BMNH 74.4.29.945), an adult male, SVL 29.0, as lectotype of this nominal taxon.

\section{Diagnosis and comparison}

Ghatophryne can be distinguished from other bufonid genera by the combination of the following characters: small-sized adults (male SVL 26.9-30.1, $\mathrm{N}=5$; female 35.0, $\mathrm{N}=1$ ); dorsum reddish brown, ventrum dark brownish black with prominent yellowish-orange spots; head without cranial ridge, lack of parotoid glands; fingers free, toes medium webbed; skin on dorsum with sparsely granular projections especially on anterior half of the body; eggs non-pigmented, tadpoles with a suctorial disk, adapted to mountain streams throughout the life cycle (SD Biju, personal observations). Ghatophryne can be characterized in a phylogenetic framework as the most inclusive clade that contains Ansonia ornata Günther, "1876" 1875, but not Bufo melanostictus Schneider, 1799 and Ansonia hanitschi Inger, 1960 [5].

Ghatophryne is morphologically very similar to species of Ansonia, but is endemic to the southern part of the Western Ghats, while Ansonia is known only from South-East Asia (Sumatra, Borneo and Philippines).

\section{Contents}

Ghatophryne ornata (Günther, "1876" 1875) comb. nov., Ghatophryne rubigina (Pillai and Pattabiraman, 1981) comb. nov. The latter is provisionally included based on distributional data and morphological resemblances [8]. 


\section{Distribution}

Ghatophryne has only been reported from Kerala and Karnataka in the Western Ghats of India.

Description of lectotype of Ansonia ornata Günther, "I876" 1875 Medium sized frog (SVL 29.0), body rather elongate. Head slightly longer than wide (HL 8.9; HW 8.5; MN 7.2; MFE 5.4; MBE 1.3); outline of snout in dorsal view nearly oval, its length (SL 4.5) larger than the horizontal diameter of the eye (EL 3.7); loreal region vertically acute; distance between anterior margins of eyes (IFE 4.6) 1.8 times in distance between posterior margins of eyes (IBE 8.4); interorbital area (IUE 2.8) broader than upper eyelid width (UEW 2.3); tympanum (TYD 2.7) rather indistinct; supratympanic fold rather indistinct; parotoid glands absent; parietal ridges absent; tongue elongate. Forearm (FLL 7.5) shorter than hand (HAL 8.8; TFL 4.0), strong; relative length of fingers, shortest to longest: $\mathrm{I}<\mathrm{II}<\mathrm{IV}<$ III, tip of fingers enlarged, rounded, without distinct grooves, without lateral dermal fringe, webbing absent; subarticular tubercles weakly developed; supernumerary tubercles weakly developed; palmar tubercle absent, nuptial pads present. Hind limbs moderately long, shank (ShL 14.1) longer than thigh (TL 13.3), longer than distance from base of inner metatarsal tubercle to tip of toe IV (FOL 12.6), shorter than distance from heel to tip of toe IV (TFOL 19.2); relative length of toes, shortest to longest: I $<$ II $<$ V $<$ III $<$ IV, tips of toes enlarged, rounded, webbing reduced, reaching up to second subarticular tubercle on both sides of toe IV; dermal fringe along toe V absent; subarticular tubercles distinct; supernumerary tubercles weakly developed; inner metatarsal tubercle elongate (IMT 1.5), outer metatarsal tubercle smaller but distinctly raised. Skin of snout, between eyes, and upper eyelids shagreened to sparsely granular, side of head, back, flanks and dorsal part of limbs sparsely granular.

Colour of lectotype: in preservation dorsally uniform light greyish brown with a dorsal light yellowish brown patch; ventral side light brown with white irregular spots.

\section{Other specimens studied}

Ovary of single female specimen (SDB 022) had 35 nonpigmented, creamy white eggs, $1.3 \pm 0.4 \mathrm{~mm}$ in diameter. Dorsum can have continuous (SDB 6362) or discontinuous (SDB 6361) yellowish bands.

\section{Xanthophryne gen. nov}

\section{Etymology}

derived from two Greek words, 'xanthos' meaning yellow, and 'phryne' meaning toad.

\section{Type species}

Bufo koynayensis Soman, 1963, by original designation, ZSIC A1784, Shivaji Sagar lake at Koyna (= Humbarli Village), Maharashtra, collected by P. W. Soman.

\section{Diagnosis and comparison}

Xanthophryne can be distinguished from other bufonid genera by the combination of the following characters: small-sized adults (male SVL 26.5-32.9, $\mathrm{N}=12$; female SVL 33.3-35.3, $\mathrm{N}=3$ ) having light brown dorsum with a suffusion of dull chrome-yellow; head with discontinuous and weak canthal and preorbital ridges on the anterior part, flanks and sides of the abdomen have chromeyellow patches, or sometimes 2-4 continuous bands; tympanum indistinct, rather weak parotoid glands; toes and fingers without webbing, tips rounded; eggs in clutches. Xanthophryne can be characterized in a phylogenetic framework as the most inclusive clade that contains Bufo koynayensis Soman, 1963 but not Bufo melanostictus Schneider, 1799 and Bufo kelaartii Günther, 1858.

\section{Contents}

Xanthophryne koynayensis (Soman, 1963) comb. nov. (Figure 2) and Xanthophryne tigerinus sp. nov. (Figure 3A)

\section{Distribution}

Xanthophryne has only been reported from the northern part of the Western Ghats of India.

\section{Xanthophryne tigerinus sp. nov.(Figure $3 A-E$ ) Etymology}

The species epithet tigerinus is attributed to this species due to similarity in the species colour pattern to the prominent lateral stripes in Tigers (Panthera tigris).

\section{Type material}

Holotype, BNHS 5175, an adult male, SVL 30.5, collected by SDB and VG on 23 August 2002 from Amboli, $15^{\circ} 56^{\prime} \mathrm{N}, 74^{\circ} 00^{\prime} \mathrm{E}$, about $720 \mathrm{~m}$ asl, Sindhudurg, Maharashtra, India; paratypes, BNHS 5177, an adult male, BNHS 5176, an adult female, collected along with the hol-

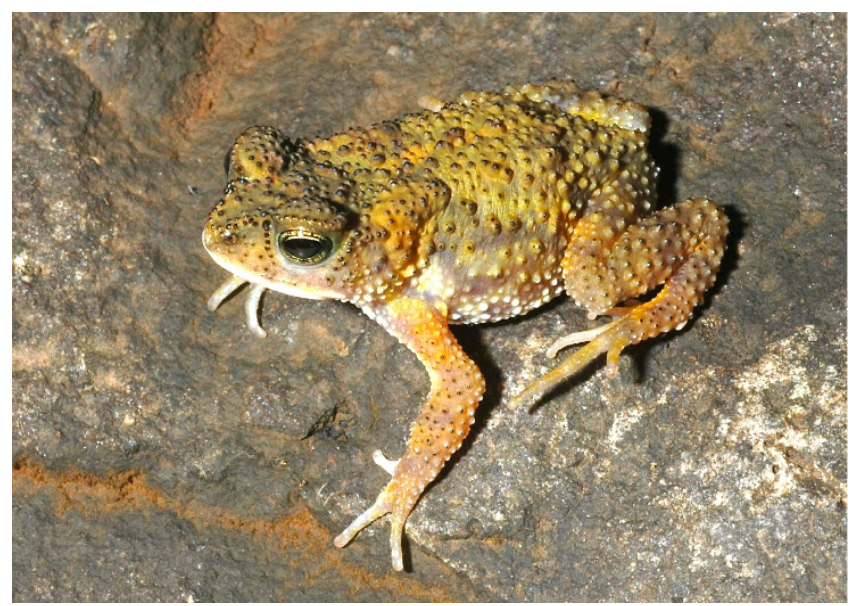

Figure 2

Xanthophryne koynayensis, a male adult (SDB 6040) from the type locality. 


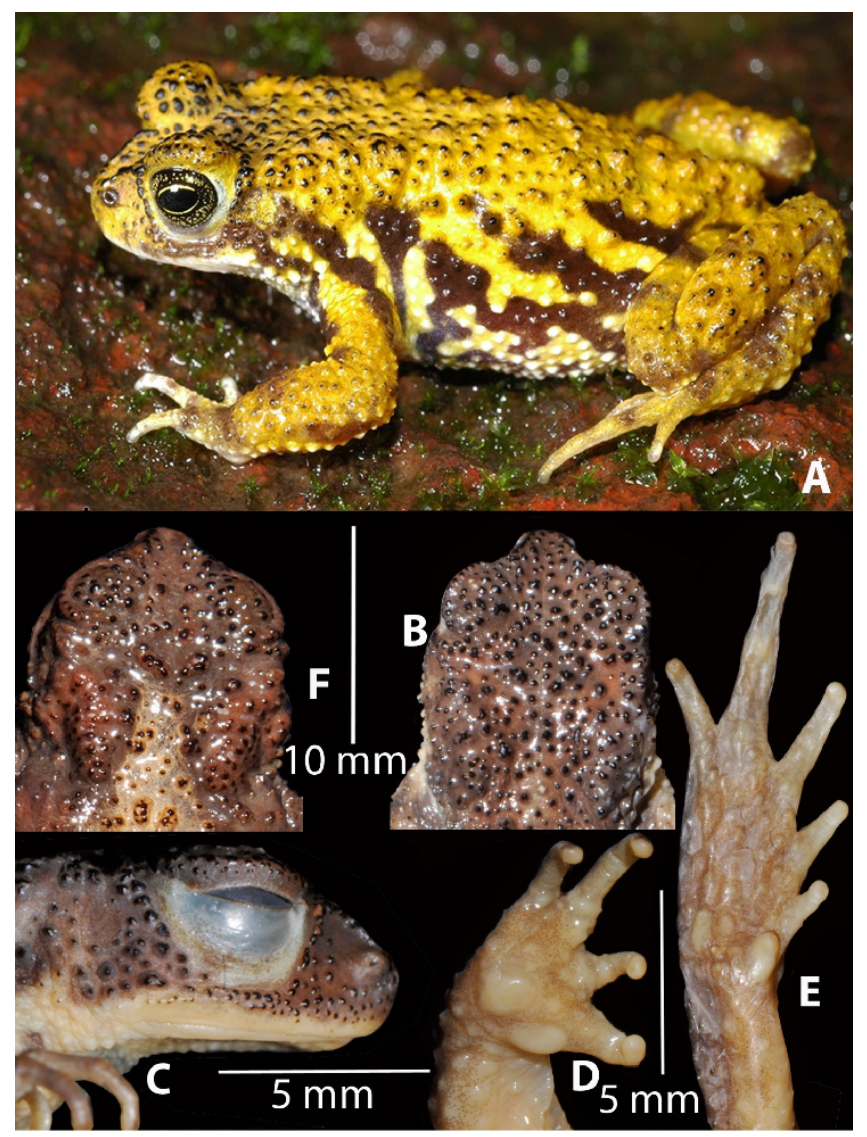

Figure 3

Xanthophryne tigerinus sp. nov (holotype, BNHS

$\mathbf{5} 1 \mathbf{7 5})$. A, holotype in life; $B$, dorsal view of head showing prominent granular projections with horny spinules; C, lateral view of head; $D$, ventral view of hand; $E$, ventral view of foot; F. Xanthophryne koynayensis, dorsal view of the head, showing scattered granular projections with horny spinules.

otype; BNHS 4064, an adult male, BNHS 4063, an adult female, collected by VG \& Hegde on 9 September 2000, BNHS 4208-4209, two males, BNHS 4207, an adult female, collected by Kehimkar and Agarwal on 16 August 2003.

\section{Diagnosis and comparison}

Xanthophryne tigerinus can be distinguished by the following combination of characters: (1) medium size, male adult SVL 27.8-32.9, female adult SVL 33.3-35.3; (2) body rather elongate; (3) presence of discontinuous canthal and preorbital ridges; (4) stripes on lateral and dorsal side; (5) absence of webbing between fingers and toes.

Xanthophryne tigerinus sp. nov. (Figure 3A-E) differs from $X$. koynayensis (Figure 2, 3F) by the presence of a denser arrangement of granular projections with horny spinules on dorsal and lateral parts of head, back and flank; more prominent canthal and preorbital ridges; snout longer than eye length (SL $4.0 \pm 0.3 \mathrm{~mm}$, EL $3.4 \pm 0.5 \mathrm{~mm}, N=$ 5 , male) vs. snout shorter than eye length (SL $3.3 \pm 0.3$ $\mathrm{mm}$, EL $4.3 \pm 0.2 \mathrm{~mm}, N=7$, male); shank longer than thigh (ShL $11.5 \pm 0.6 \mathrm{~mm}$, TL $9.9 \pm 0.4 \mathrm{~mm}, N=5$, males) vs. shank about equal to thigh (ShL $11.1 \pm 0.7 \mathrm{~mm}$, TL $11.1 \pm 0.8 \mathrm{~mm}, N=7$, male); foot length longer than shank and thigh (FOL $12.8 \pm 0.6, N=5$, male) vs. equal to shank and thigh (FOL $11.2 \pm 0.7, N=7$, male).

\section{Description of the holotype}

Medium sized frog (SVL 30.5), body rather elongate (Figure $3 \mathrm{~A}$ ). Head length subequal (HL 10.1) to head width (HW 10.3; MN 8.8; MFE 7.2; MBE 4.2) (Figure 3B, C); outline of snout in dorsal view nearly oval, in ventral view oval to pointed, its length (SL 4.1) longer than the horizontal diameter of the eye (EL 3.1); loreal region vertically acute; distance between anterior margins of eyes (IFE 4.6) 1.9 times in distance between posterior margins of eyes (IBE 8.7); interorbital area (IUE 2.3) less than upper eyelid (UEW 3.1); tympanum rather indistinct; supratympanic fold absent; parotoid glands present, rounded; canthal and preorbital ridges well developed, continuous; tongue entire, oval. Forearm (FLL 6.1) shorter than hand (HAL 7.0; TFL 3.5); relative length of fingers, shortest to longest: I < II < IV < III (Figure 3D), tip of fingers enlarged, rounded, without distinct grooves, without lateral dermal fringe, webbing absent; subarticular tubercles weakly developed; prepollex rounded, prominent, palmar tubercle one, rounded, prominent; supernumerary tubercles weakly developed; nuptial pads present. Hindlimbs moderately long, shank (ShL 11.8) longer than thigh (TL 10.1), shorter than distance from base of inner metatarsal tubercle to tip of toe IV (FOL 13.1); distance from heel to tip of toe IV (TFOL18.1); relative length of toes, shorter to longest: $\mathrm{I}<\mathrm{II}<\mathrm{III}<\mathrm{V}<\mathrm{IV}$ (Figure 3E), tips of toes enlarged, rounded, webbing absent; subarticular tubercles rather indistinct; supernumerary tubercles weakly developed; inner metatarsal tubercle elongated (IMT 1.2). Skin of snout, between eyes, upper eyelids, side of head, and back have granular projections with horny spinules; dorsal part of limbs granular with horny spinules; throat shagreened to granular; chest, belly, and posterior surface of thighs granular.

Color: in preservation: dorsum light-brown, loreal and tympanic region light brown, lateral region dark grey with light colour stripes; fingers I and II, and toes I and II creamy white; ventral side light brownish grey with dark grey irregular spots; in life: dorsum golden yellow, lateral region brown with light yellow stripes extending from dorsum; fingers I and II, and toes I and II whitish; ventral side light grey with dark greyish brown irregular spots, lower jaw margins white. 


\section{Secondary sexual characteristics}

Male (BNHS 5175) has nuptial spines on the prepollex; Ovary of single female specimen ((BNHS 4207) had 59 pigmented eggs, $1.2 \pm 0.3 \mathrm{~mm}$ in diameter.

\section{Variation}

Measurements of eight type specimens are given in Table 1. During the breeding season, both male and female toads have a bright yellow dorsum with light yellow and light blue lateral stripes. Outside the breeding season, they have a light brownish grey dorsum with light yellow lateral stripes.

\section{Distribution and natural history}

Xanthophryne tigerinus sp. nov. is known only from the type locality Amboli. The type series was collected from the ground near disturbed evergreen forest patches during a rainy evening after 19:00 h. Amplexus is axillary. Egg clutches contain 30-35 eggs per clutch $(N=4$; VG, per- sonal observation). The eggs are laid in temporary puddles on laterite rocks (Figure 4).

Notes

Bufo koynayensis Soman, 1963 was described twice based on the same type series but bearing different numbers. Soman first described Bufo koynayensis, without designating any type other than mentioning, "was collected in good numbers" [9]. Almost 40 years later, specimen ZSI A.1784 was recognized as the holotype of Bufo koynayensis Soman, 1963 [10]. This specimen was examined and is badly damaged (SDB, personal observation). The samples collected by Soman were utilized to describe Bufo sulphureus (holotype, BNHS 377 and 26 paratypes including 5 males, 11 females and 10 juveniles) [11], which as a consequence is a junior synonym of Bufo koynayensis. As described in the original description, the type series of Bufo sulphureus were deposited in the British Museum of Natural History, the Indian Museum and the Bombay

Table I: Measurements of the two Xanthophryne gen. nov. species

\begin{tabular}{|c|c|c|c|c|c|c|c|c|c|c|c|c|}
\hline \multicolumn{13}{|c|}{ Xanthophryne tigerinus sp. nov. (type series) } \\
\hline & \multicolumn{6}{|c|}{ Male } & \multicolumn{6}{|c|}{ Female } \\
\hline & $\begin{array}{c}\text { BNHS } \\
5175\end{array}$ & $\begin{array}{c}\text { BNHS } \\
5177\end{array}$ & $\begin{array}{c}\text { BNHS } \\
4064\end{array}$ & $\begin{array}{c}\text { BNHS } \\
4208\end{array}$ & $\begin{array}{c}\text { BNHS } \\
4209\end{array}$ & Mean & STDV & $\begin{array}{c}\text { BNHS } \\
5176\end{array}$ & $\begin{array}{c}\text { BNHS } \\
4063\end{array}$ & $\begin{array}{c}\text { BNHS } \\
4207\end{array}$ & Mean & STDV \\
\hline SVL & 30.5 & 31.0 & 32.9 & 32.0 & 27.8 & 30.8 & 1.9 & 33.9 & 33.3 & 35.3 & 34.2 & 1.0 \\
\hline $\mathrm{HW}$ & 10.3 & 10.1 & 11.0 & 10.2 & 10.1 & 10.3 & 0.4 & 12.2 & 11.5 & 13.9 & 12.5 & 1.2 \\
\hline $\mathrm{HL}$ & 10.1 & 10.0 & 10.7 & 10.1 & 9.0 & 10.0 & 0.6 & 11.2 & 10.9 & 12.2 & 11.4 & 0.7 \\
\hline IUE & 2.3 & 2.1 & 2.3 & 2.1 & 2.5 & 2.3 & 0.2 & 2.3 & 2.5 & 3.0 & 2.6 & 0.4 \\
\hline UEW & 3.1 & 2.9 & 3.6 & 3.1 & 2.9 & 3.1 & 0.3 & 3.4 & 3.4 & 3.2 & 3.3 & 0.1 \\
\hline SL & 4.1 & 3.6 & 4.5 & 4.1 & 3.8 & 4.0 & 0.3 & 4.5 & 4.8 & 4.6 & 4.6 & 0.2 \\
\hline EL & 3.1 & 3.0 & 4.0 & 4.0 & 3.0 & 3.4 & 0.5 & 4.4 & 4.6 & 4.5 & 4.5 & 0.1 \\
\hline FLL & 6.1 & 6.8 & 5.4 & 6.5 & 5.8 & 6.1 & 0.6 & 7.4 & 6.1 & 6.1 & 6.5 & 0.8 \\
\hline HAL & 7.0 & 6.9 & 6.7 & 6.8 & 6.7 & 6.8 & 0.1 & 6.7 & 6.9 & 7.4 & 7.0 & 0.4 \\
\hline ShL & 11.8 & 11.9 & 11.8 & 11.7 & 10.4 & 11.5 & 0.6 & 11.6 & 11.7 & 12.2 & 11.8 & 0.3 \\
\hline $\mathrm{TL}$ & 10.1 & 10.2 & 9.3 & 10.3 & 9.7 & 9.9 & 0.4 & 10.7 & 8.8 & 11.6 & 10.4 & 1.4 \\
\hline FOL & 13.1 & 12.8 & 13.4 & 12.6 & 11.9 & 12.8 & 0.6 & 12.6 & 13.2 & 13.9 & 13.2 & 0.7 \\
\hline \multicolumn{13}{|c|}{ Xanthophryne koynayensis } \\
\hline & & & & & & Males & & & & & & \\
\hline & $\begin{array}{c}\text { BNHS* } \\
377\end{array}$ & $\begin{array}{c}\text { BNHS } * * \\
357\end{array}$ & $\begin{array}{c}\text { BNHS** } \\
358\end{array}$ & $\begin{array}{c}\text { BNHS** } \\
372\end{array}$ & $\begin{array}{c}\text { BNHS } \\
36 * *\end{array}$ & $\begin{array}{c}\text { BNHS } \\
5174\end{array}$ & $\begin{array}{c}\text { BNHS } \\
5188\end{array}$ & Mean & STDV & & & \\
\hline SVL & 29.6 & 29.8 & 31.8 & 31.1 & 31.2 & 27.1 & 26.5 & 29.6 & 2.1 & & & \\
\hline $\mathrm{HW}$ & 11.1 & 10.3 & 11.0 & 11.0 & 10.9 & 10.6 & 10.5 & 10.8 & 0.3 & & & \\
\hline $\mathrm{HL}$ & 10.6 & 10.0 & 11.4 & 10.2 & 10.0 & 8.4 & 9.1 & 10.0 & 1.0 & & & \\
\hline IUE & 2.4 & 2.0 & 2.4 & 2.4 & 2.2 & 2.5 & 2.7 & 2.4 & 0.2 & & & \\
\hline UEW & 3.3 & 2.8 & 3.1 & 3.1 & 3.1 & 3.1 & 3.2 & 3.1 & 0.2 & & & \\
\hline SL & 3.2 & 3.1 & 3.2 & 3.7 & 3.8 & 3.2 & 3.2 & 3.3 & 0.3 & & & \\
\hline EL & 4.1 & 4.2 & 4.2 & 4.7 & 4.5 & 4.2 & 4.2 & 4.3 & 0.2 & & & \\
\hline $\mathrm{FLL}$ & 6.2 & 5.3 & 5.8 & 5.8 & 6.2 & 5.2 & 6.0 & 5.8 & 0.4 & & & \\
\hline HAL & 6.3 & 6.0 & 7.1 & 7.6 & 7.3 & 6.0 & 7.1 & 6.8 & 0.7 & & & \\
\hline ShL & 11.8 & 10.1 & 11.5 & 11.3 & 11.5 & 10.2 & 11.2 & 11.1 & 0.7 & & & \\
\hline $\mathrm{TL}$ & 11.9 & 10.0 & 11.6 & 11.2 & 11.6 & 10.1 & 11.3 & 11.1 & 0.8 & & & \\
\hline FOL & 11.9 & 10.2 & 11.5 & 11.4 & 11.5 & 10.3 & 11.5 & 11.2 & 0.7 & & & \\
\hline
\end{tabular}

* holotype and ** paratype of Bufo sulphureus Grandison and Daniel, 1964. 


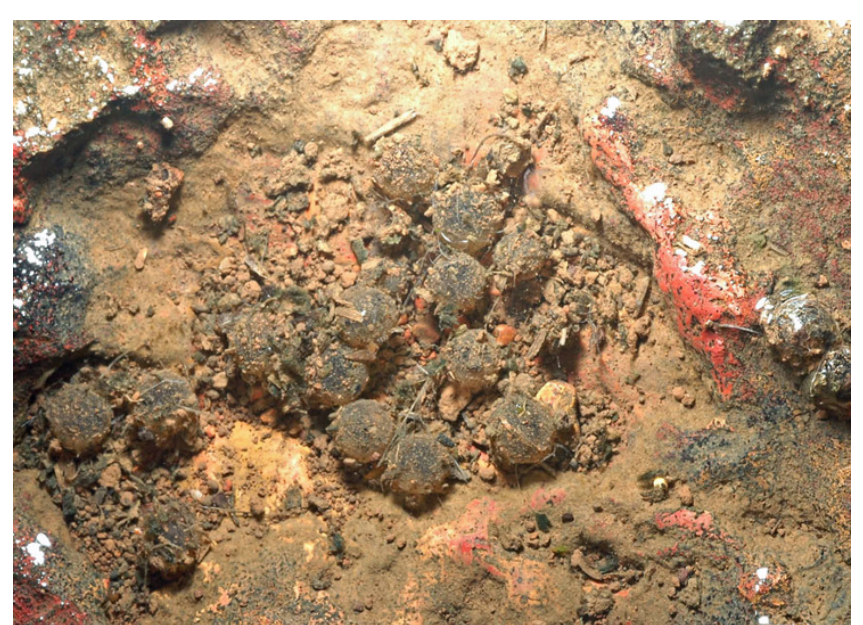

Figure 4

Xanthophryne tigerinus eggs are laid in clutches in temporary puddles.

Natural History Society. In this study, we examined the holotype and 18 paratypes (14 adult males - SVL 24.0$31.8 \mathrm{~mm}$ and 4 subadults - SVL 20.9-25.0 $\mathrm{mm}$ ) deposited in BNHS and five paratypes in BMNH under the nomen 'Bufo sulphureus'. In addition, recent collections of 'Bufo' koynayensis from the type locality were compared. All available material of this species is consistent with the original description.

\section{Conclusion}

Ghatophryne gen. nov. and Xanthophryne gen. nov. are both endemic to the Western Ghats of India. Together with the arboreal toad genus Pedostibes (Western Ghats endemic; species from South-East Asia belong to another clade) and the genus Adenomus (Sri Lanka endemic), they form the oldest lineages in the Adenominae clade. The recognition of each of these lineages as distinct genera highlights their early diversification on the southern parts of the Indian subcontinent [5].

\section{Competing interests}

The authors declare that they have no competing interests.

\section{Authors' contributions}

All authors contributed equally, and read and approved the final manuscript.

\section{Acknowledgements}

We thank G. Ramakrishna and Kausik Deuti (ZSI), Asad Rahmani, J.C. Daniel (BNHS) and B. Clarke (NHM) for their support in our studies. Anil Zacharya, Kehimkar, I. Agarwal and V. Patil provided valuable support in the field; I. Das provided valuable literature; I. Agarwal and Hemant Ogale made photographs of Xanthophryne available. The State Forest Departments of Kerala and Maharashtra kindly provided study permits to SDB and VG, and are greatly acknowledged. SDB is grateful to the Ministry of Environment and Forest (MoEF) and University of Delhi (Scheme to strengthen R\&D and Doctoral Research Program) for funds for the research. IVB is supported by a research grant from the Institute for the Promotion of Innovation through Science and Technology in Flanders (IWT-Vlaanderen). FB receives a postdoctoral fellowship from the Fonds voor Wetenschappelijk Onderzoek-Vlaanderen (FWO). Financial support was provided FWO-Vlaanderen (grants FWO I.5.039.03N, FWO G.0056.03, FWO G.0307.04) and the Vrije Universiteit Brussel (grant VUB OZR834).

\section{References}

I. Frost DR, Grant T, Faivovich J, Bain RH, Haas A, Haddad CFBdS RO, Channing A, Wilkinson M, Donnellan SC, Raxworthy CJ, et al:: The amphibian tree of life. Bull Am Mus Nat Hist 2006, 297: I-370.

2. Smith HM, Chiszar D: Dilemma of name-recognition: Why and when to use new combinations of scientific names. Herpetological Conservation and Biology 2006, I(I):6-8.

3. Pramuk JB, Robertson T, Sites JW, Noonan BP: Around the world in 10 million years: Biogeography of the nearly cosmopolitan true toads (Anura: Bufonidae). Global Ecol Biogeogr 2007, 17:72-83.

4. Pauly GB, Hillis DM, Cannatella DC: The history of a Nearctic colonization: Molecular phylogenetics and biogeography of the neartic toads (Bufo). Evolution 2004, 58(II):2517-2535.

5. Van Bocxlaer I, Biju S, Loader S, Bossuyt F: Toad radiation reveals into-India dispersal as a source of endemism in the Western Ghats-Sri Lanka biodiversity hotspot. BMC Evolutionary Biology 2009, 9( I 3 I): I- I0.

6. Dubois $\mathrm{A}$ : La nomenclature supragénérique des Amphibiens Anoures. Mémoires du Muséum national d'histoire naturelle 1984, série A, Zoologie, 13 1: 1-64.

7. Biju SD, Bossuyt F: Systematics and phylogeny of Philautus gistel, 1848 (Anura, rhacophoridae) in the Western Ghats of India, with descriptions of $\mathbf{I} 2$ new species. Zool J Linn Soc 2009, 155(2):374-444.

8. Pillai RS, Pattabiraman R: A new species of torrent toad (genus: Ansonia) from silent valley, s. India. Proc Indian Acad Sci (Anim Sci) 1981, 90(2):203-208.

9. Soman PW: A new Bufo from maharashtra. Journal of Biological Science Bombay 1963, 6:74.

10. Chanda KS, Das I, Dubois A: Catalogue of amphibian types in the collection of the zoological survey of India. Hamadryad 2000, 25(2): 100- 128.

II. Grandison AG, Daniel JC: Description of a new species of toad from surat district, maharashtra, India. Journal Bombay Natural History Society 1964, 61:192-194.
Publish with BioMed Central and every scientist can read your work free of charge

"BioMed Central will be the most significant development for disseminating the results of biomedical research in our lifetime. "

Sir Paul Nurse, Cancer Research UK

Your research papers will be:

- available free of charge to the entire biomedical community

- peer reviewed and published immediately upon acceptance

- cited in PubMed and archived on PubMed Central

- yours - you keep the copyright

Submit your manuscript here:

http://www.biomedcentral.com/info/publishing_adv.asp
BioMedcentral 